OPEN ACCESS

Edited by:

Violeta Enea,

Alexandru loan Cuza

University, Romania

Reviewed by:

Barbara Bętkowska-Korpała, Jagiellonian University Medical

College, Poland

Taofeng Liu,

Zhengzhou University, China

*Correspondence:

Małgorzata Lipowska

malgorzata.lipowska@ug.edu.pl

Specialty section:

This article was submitted to

Psychopathology,

a section of the journal

Frontiers in Psychiatry

Received: 02 October 2021

Accepted: 18 October 2021

Published: 11 November 2021

Citation:

Mazurkiewicz N, Krefta J and Lipowska M (2021) Attitudes Towards Appearance and Body-Related Stigma Among Young Women With

Obesity and Psoriasis.

Front. Psychiatry 12:788439. doi: 10.3389/fpsyt.2021.788439

\section{Attitudes Towards Appearance and Body-Related Stigma Among Young Women With Obesity and Psoriasis}

\author{
Natalia Mazurkiewicz ${ }^{1}$, Jarosław Krefta ${ }^{2}$ and Małgorzata Lipowska ${ }^{1 *}$ \\ ${ }^{1}$ Institute of Psychology, University of Gdańsk, Gdansk, Poland, ${ }^{2}$ Creative Code Studio, Gdynia, Poland
}

The goal of this study was to investigate the role of the subjective assessment of one's body image in the relationship between objective indices of appearance and perceived stigma in young women affected by obesity and psoriasis. These are chronic diseases that decrease one's physical attractiveness and are associated with stigmas related to body defects. A total of 188 women in early adulthood took part in the study $(M=$ 25.58; $S D=2.90)$, including obese women $(n=54)$, women suffering from psoriasis ( $n$ $=57$ ), and a control group $(n=77)$. The participants completed the Multidimensional Body-Self Relations Questionnaire, Perceived Stigmatisation Questionnaire, and a socio-demographic questionnaire. Anthropometric data were gathered using a body composition analyzer. Objective parameters of body shape were calculated (WHR and ICO). Subjective assessment of one's body and attitudes towards one's body were found to influence perceived stigma, independently of the condition causing the stigma and of the objective appearance of the participant. This study did not support the existence of a relationship between parameters regarding body shape and sense of stigma, even when subjective body assessment acted as a moderator. At the same time, body mass was a strong predictor of levels of perceived stigma. Women affected with obesity perceived a higher level of stigma than the other groups. The severity of psoriasis did not impact the perceived stigma. Moreover, women with psoriasis assessed their health-as a part of the assessment of their bodies - the highest, which may explain the lower perceived stigma in this group.

\section{Keywords: body attitude, body image, body stigma, obesity, skin disease}

\section{INTRODUCTION}

Body image, assessment of one's body, and attitudes towards one's body are important elements of the development of the "self" (1). Research suggests that how we perceive our body is more important for our body image than its actual appearance $(2,3)$. This is important, because one's body image and sense of attractiveness are strongly associated with self-esteem $(4,5)$, well-being (6), happiness $(7,8)$, life satisfaction (9), and it influences health-related quality of life (10-12). Our attitudes towards our bodies are shaped and change throughout the different stages of our lives. Assessment of one's body decreases significantly during adolescence and early adulthood-mainly because of judgement from one's environment (13-15) -increases slowly during mid-adulthood $(16)$, and then rapidly drops when one reaches old age $(17,18)$. People tend to be most critical of their bodies during adolescence and young adulthood (19), and the imperfections typical of 
teenage bodies are often used by peers as a source of mockery or rejection $(20,21)$. The shaping of one's body image is influenced by attitudes and beliefs regarding one's body (subjective opinions and perceptions, such as satisfaction or dissatisfaction with one's looks), physical factors (objective body measurements, proportions, body mass, height), interpersonal factors (opinions from one's environment; e.g., family members, peers), and cultural factors (e.g., from the media) $(1,22)$. The latter have a huge influence over the "ideal" an individual tries to attain, because they play a significant role in the acceptance and construction of standards for bodies (23). Western culture promotes body ideals characterised by tall, slim female bodies $(24,25)$, with constant breasts-to-waist ratio and a low hip-towaist ratio $(26,27)$, while perfect male bodies are muscular and mesomorphic (V-shaped, with broad shoulders and a narrow waist) $(28,29)$.

Thus, the way a person views their body depends not only on their culture (30-33) and age $(16,17)$, but also on their gender (34). Body image is a much more important part of the "self" for girls and women than it is for men, and thus it directly and strongly shapes their overall levels of self-esteem $(35,36)$. In comparison to men, women are more prone to negative body-image evaluations and pay more attention to their looks (37); furthermore, they are subject to greater pressure from the media regarding their body shape (31). Physical attractiveness also influences the way that an individual is treated. The so-called "halo effect" is when a person who possesses one positive feature is perceived as therefore having other positive features (38). Thus, individuals who would be considered unattractive or physically ugly are more likely to be perceived as having negative features. Even in children's stories, ugliness or a visible disability is often a marker of evil (39-41).

Fear of being unattractive, not fitting into the norms, or even being rejected due to one's looks may lead to serious mental disorders. Attitudes towards one's body are an important element of disorders such as anorexia and bulimia nervosa (42) as well as body dysmorphic disorder (43, 44). Shame and the sense of humiliation associated with the perception that one's environment can see one's flaws-skin problems, for example-and the fear of being rejected or isolated by "healthy" individuals may lead to mental health problems such as depression, addiction, or anxiety disorders (45). Individuals suffering from depression tend to focus more on their body mass and they may ruminate about their extra weight (46). There also exists a relationship between increased body mass and decreased mental health (47). Moreover the difference between actual ("real self") and idealised ("ideal self") body shape among young women increases emotional discomfort, anxiety, fear, and internal tension (48) Unattractive looks that do not "fit the norm" may thus be a major source of stigma (49).

A feature, mark, or social attribute may be the cause of deep stigmatisation. People suffering from such stigmas may be perceived as different, lesser, or even dehumanised (50). Unattractive looks and body imperfections (such as pimples, being too tall, too short, too fat, too skinny, etc.) are one of the most important sources of stigma, alongside character imperfections (laziness, mental illness, dishonesty) and identity (attached to identification with a particular race, ethnicity, religion, ideology, etc). Certain bodily imperfections (e.g., chronic skin diseases or prosthetic limbs) can be hidden, not immediately visible, and thus discreditable. In such situations, a person may decide whether and under what circumstances they will disclose their imperfection. A visible feature that cannot be disguised, such as height, obesity, or skin colour, is discredited because of its being clearly visible $(51,52)$. Someone who is thus stigmatised often experiences exclusion or rejection and their imperfection can become their defining attribute (53).

The difference between discredited and discreditable stigmas means that the assessment of attractiveness and the level of stigma differ depending on the context. Dermatological conditions and obesity are chronic health problems that impact one's sense of attractiveness, significantly lowering one's physical attractiveness and influencing quality of life (11, 54-58). However, a person with a visible skin condition (e.g., psoriasis or atopic dermatitis) is perceived differently than are obese ("fat") individuals: the environment "blames" an individual for being obese (11). Psoriasis or atopic dermatitis are genetic conditions whose occurrence is outside the control of the person affected $(59,60)$. Psoriasis is a chronic disease that may undergo periods of remission, during which the condition improves and the associated problems may even disappear completely; however, it is impossible to completely cure it and prevent relapse (45). Obesity is a chronic disease characterised by the ratio between one's body mass and height squared being above 30 (61), and an individual's choices can play a role in the aetiology of the condition (it is commonly perceived that one can change their looks/body mass through exercise, diet, medication, or, in the most serious cases, by surgery). Thus, the stigma around obesity is two-fold: both the appearance (bodily imperfection) and character imperfection are stigmatised $(49,52)$.

Therefore, the goal of the current study was to investigate the role of subjective assessment of one's body in the relationship between objective indices of one's looks (body shape, body mass, presence of a skin condition) and the sense of stigma among young women.

To this end, the following hypotheses were formulated:

1. The level of perceived stigma will depend on the type of stigma: young women who are obese will experience the greatest sense of stigma due to being affected by a double stigma; the lowest levels of stigma will be experienced by the women in the control group.

2. Attitude towards one's body will be a moderator of the relationship between the objective parameters of the stigmacausing condition and the sense of stigma.

\section{MATERIALS AND METHODS}

\section{Participants}

A total of 188 young adult women took part in the study (age: $M$ $=25.58 ; S D=2.90 ; \min =19, \max =30$ ); we chose a young study group on purpose, as this is a developmental period in which body image is very important and assessments thereof are the most critical (19). We selected two groups of women who 
have conditions that affect how one looks: obesity and psoriasis. Despite the fact that these conditions often co-occur (62), we focused on groups of women with only obesity [as per WHO $\mathrm{BMI} \geq 30, n=54$; (61)] or psoriasis (the inclusion criteria were at least 1 year having elapsed since diagnosis and visible skin lesions; $n=57$ ). In order to assess whether the investigated phenomena occur only for the group with the visible stigmatising conditions, women with normal weight and no skin conditions were also included in the study (control group; $n=77$ ). None of the study participants underwent bariatric surgery or laser skin therapy.

\section{Procedure}

The recruitment procedure had two stages. During the first stage, females participating in a larger project, described elsewhere (63), who met the inclusion criteria for this study were recruited. During the second stage, females who met the inclusion criteria for this research project were asked to invite acquaintances to participate-i.e. a non-random method of sample selection ["snowball sampling technique"; (64)]. A total sample of 188 females was recruited for this study. Data were collected between 2018 and 2019.

Participants completed the following questionnaires: the Perceived Stigmatisation Questionnaire, the Multidimensional Body-Self Relations Questionnaire, and a short survey to collect medical and sociodemographic variables. These questionnaires were completed during a visit to a dietician, dermatologist, or psychologist, or at home (in this case, participants had 2 weeks to complete the questionnaires). Additionally, we collected objective body measurements: body mass, height, and sizes of individual body parts. This allowed us to calculate anthropometric indices for all participants, such as Body Mass Index (BMI), Index Of Central Obesity (ICO), and Waist-toHip Ratio (WHR). Moreover, the objective body parameters connected with body mass were controlled using a body composition analyzer. The data used for this study were part of a larger survey and the questionnaires that formed this study took around $25 \mathrm{~min}$ to complete.

The protocol of this study was approved by the Ethics Board for Research Projects at the Institute of Psychology, University of Gdansk, Poland (decision no. 12/2018).

\section{Multidimensional Body-Self Relations Questionnaire}

We used the Multidimensional Body-Self Relations Questionnaire (65), in its Polish adaptation (66), to measure the participants' body-image. This questionnaire is composed of 69 statements that assess the participants' attitudes towards their body's appearance. The scale has 10 subscales clustered into four areas: Appearance-Appearance Evaluation (AE), Appearance Orientation (AO), and Body Areas Satisfaction (BAS); Fitness-Fitness Evaluation (FE) and Fitness Orientation (FO); Health-Health Evaluation (HE) and Health Orientation (HO); Illness Orientation (IO); and Body Weight-Overweight Preoccupation (OP) and Self-classified Weight (SCW). Participants give their responses on a five-point Likert type scale ranging from 1 (definitely disagree) to 5 (definitely agree).
The indicators are slightly different for some items: 1 (never), 2 (rarely), 3 (sometimes), 4 (often), and 5 (very often).

\section{Perceived Stigmatisation Questionnaire}

The Perceived Stigmatisation Questionnaire was used to assess sense of stigma in the young women (67). The questionnaire is composed of 21 items that form 3 subscales: Absence of Friendly Behaviour, Confused/Staring Behaviour, Hostile Behaviour, and Total Score. Participants assess on a five-point Likert-like scale how often people behave in certain ways around them, where 1 indicates never, 3 indicates sometimes, and 5 indicates always. In order to develop a Polish version of the PSQ, the questionnaire was translated into Polish independently by an interpreter and a psychologist with the author's consent. After selecting the best Polish version, it was back-translated into English by a native speaker. Then, the quality of translation was assessed by comparing the back-translation with the original questionnaire.

\section{Sociodemographic Questionnaire}

The sociodemographic questionnaire was composed of questions about age, height, marital status, place of residence (city, town, village), concomitant diseases, the diets one follows, as well as visits to specialist physicians and dieticians. With regards to dermatology, we asked about the severity of the condition and methods used to conceal or treat the visible skin lesions. In the part regarding body mass and shape, we used the body measurement data to calculate anthropometric indices.

\section{Body Composition Analyzer}

In order to measure the objective dimensions of the body and its components, we used the Segmental Body Composition Monitor-Tanita BC-601, produced by Tanita Corporation, Japan. BMI was calculated only as an inclusion criterion for the obesity group. The importance of body composition and visceral fat levels is increasingly emphasised $(68,69)$, which is why BMI was not used in further analyses. For adults, the analyzer allows the measurement of indices of obesity level adjusted for muscle mass content, fat percentage $(\% \mathrm{BF})$, recommended daily energetic intake, basal metabolic rate, metabolic age, bone mass, and visceral fat content (70).

\section{Anthropometric Indices}

Indices related to body shape were calculated based on a questionnaire prepared for the purposes of this study.

Index of central obesity (ICO): the ratio between waist circumference and height. This allows the assessment of the ratio between visceral fat and the total fat content. It is a more precise parameter for gauging one's health, because it takes visceral fat levels into account. It is also important for the parameters of one's body shape (71).

We also calculated the Waist-to-hip ratio (WHR), which is an index of body shape. It usually takes values between 0.6 and $1.0-$ the lower the index, the slimmer the waist in comparison to the hips (hourglass figure; $(26,72)$.

\section{Statistical Analysis}

The analyses were performed in Python 3.8.5 programming language (Python Software Foundation, USA, 512 Lafayette 
TABLE 1 | Anthropometric differences between the groups.

\begin{tabular}{|c|c|c|c|c|c|c|c|c|c|c|}
\hline \multirow{2}{*}{$\begin{array}{l}\text { Anthropometric } \\
\text { parameters }\end{array}$} & \multicolumn{2}{|c|}{ Control group $(n=77)$} & \multicolumn{2}{|c|}{ Women with obesity $(n=54)$} & \multicolumn{2}{|c|}{ Women with psoriasis $(n=57)$} & \multicolumn{4}{|c|}{ ANOVA } \\
\hline & $M$ & $S D$ & $M$ & $S D$ & $M$ & $S D$ & $\boldsymbol{F}$ & $p$ & $\eta^{2}$ & DIFF \\
\hline Body mass & 61.07 & 6.00 & 98.17 & 15.14 & 60.92 & 7.90 & 267.72 & $<0.001$ & 0.07 & $\mathrm{O}>\mathrm{C} ; \mathrm{O}>\mathrm{P}$ \\
\hline BMl & 21.74 & 1.64 & 35.01 & 4.14 & 22.04 & 2.21 & 442.46 & $<0.001$ & 0.08 & $\mathrm{O}>\mathrm{C} ; \mathrm{O}>\mathrm{P}$ \\
\hline WHR & 0.79 & 0.07 & 0.89 & 0.08 & 0.81 & 0.09 & 26.62 & $<0.001$ & 0.02 & $\mathrm{O}>\mathrm{C} ; \mathrm{O}>\mathrm{P}$ \\
\hline $\mathrm{ICO}$ & 0.45 & 0.04 & 0.63 & 0.07 & 0.47 & 0.05 & 221.03 & $<0.001$ & 0.07 & $\mathrm{O}>\mathrm{C} ; \mathrm{O}>\mathrm{P}$ \\
\hline$\% \mathrm{BF}$ & 28.56 & 3.75 & 43.44 & 4.91 & 27.23 & 6.07 & 193.88 & $<0.001$ & 0.06 & $\mathrm{O}>\mathrm{C} ; \mathrm{O}>\mathrm{P}$ \\
\hline Visceral fat & 1.86 & 0.79 & 8.62 & 2.47 & 2.07 & 1.19 & 352.18 & $<0.001$ & 0.08 & $\mathrm{O}>\mathrm{C} ; \mathrm{O}>\mathrm{P}$ \\
\hline Age & 25.56 & 2.81 & 26.19 & 2.62 & 25.04 & 3.18 & 2.22 & 0.11 & 0.02 & - \\
\hline High & 167.52 & 6.07 & 167.37 & 5.36 & 166.00 & 5.45 & 1.31 & 0.27 & 0.01 & - \\
\hline $\begin{array}{l}\text { Disease } \\
\text { severity }\end{array}$ & 1.01 & 0.72 & 1.02 & 0.84 & 5.51 & 1.73 & 303.75 & $<0.001$ & 0.07 & $\mathrm{O}>\mathrm{C} ; \mathrm{P}>\mathrm{O} ; \mathrm{P}>\mathrm{C}$ \\
\hline
\end{tabular}

C, Control Group; O, Women with obesity; P, Women with Psoriasis; $\eta^{2}$, magnitude of effect.

Boulevard, Suite 2, Fredericksburg, Virginia 22401) programming language, using JupiterLab 2.2.6(Open Source Software) as the computation environment.

The following python libraries were used:

- pandas 1.1.3 (Open Source Software);

- scipy 1.5.2 (Open Source Software);

- numpy 1.19.2 (Open Source Software);

- pingouin 0.3.9 (Open Source Software).

Test data were contained in pandas.DataFrame. DataFrame is a two-dimensional, size-mutable, potentially heterogeneous tabular data type. Its structure contains labelled axes (rows and columns). Arithmetic operations align on both row and column labels. It can be considered a mathematical database. This study used DataFrame to index and align data. Each row contained all data collected from a single participant.

Wilk-Shapiro test was performed using scipy.stats.shapiro function. One way Anova test was performed using pingouin.anova function. Kurskal test was performed using scipy.stats.kruskal. Spearman's Rho correlations were calculated using scipy.stats.spearmanr function. Pearson's Rho correlations were calculated using scipy.stats.pearsonr function. Z-Score was calculated by executing pandas.DataFrame.apply(numpy.mstats.zscore). Moderation was calculated using python implementation of prof. Hayes, A. F. PROCESS macro. Wilk-Shapiro test was used to verify parametric assumptions on data used in the document.

As a result, non-parametric variables were found: Absence of Friendly Behaviour, Appearance Orientation (AO), Fitness Orientation (FO), Health Orientation (HO), Illness Orientation (IO).

For parametric variables, the validity of group selection was determined by using mean analysis, ANOVA, and Dunn's multiple comparison test. For non-parametric variables, the validity of group selection was determined by using mean analysis, Kruskal-Wallis $H$-test, and Tukey's range test.

Pearson Rho correlation ware calculated for parametric variables, between groups for Anthropometric Indices, PSQ, and
MBSRQ while Spearman Rho correlations were calculated for non-parametric variables.

Bias-correct, no-nparametric, bootstrap PROCESS MACRO moderation was used to determine the relationship of Anthropometric Indices, and PSQ with MBSRQ as relation moderator.

\section{RESULTS}

\section{Objective Body Dimension Differences}

First, we assessed whether groups had been selected appropriately. Their characteristics and anthropometric differences are presented in Table $\mathbf{1 .}$

The collected data indicate that the groups were selected appropriately. The groups differed in terms of the parameters that were key to the sampling process. Parameters regarding body mass and BMI were the highest in the group of women affected with obesity (Dunn post hoc analysis: $p<0.001$ ), while those regarding the phase and the severity of disease were highest in the group affected by psoriasis $(p<0.001)$. The groups did not differ in terms of age and height.

\section{Participants' Attitudes Towards Their Own Body and Their Perceived Stigma}

Attitudes towards one's own body differed between the groups (Table 2).

Women affected by obesity had the lowest satisfaction with their bodies (Tukey comparison with psoriasis: $p>0.002$; and the control group: $p=0.001$ ) and the lowest assessment of their looks (Dunn post hoc analysis: $p>0.001$ ). It is not surprising that this was associated with the assessment of one's body mass (post hoc Tukey: $p>0.001$ ) and with being preoccupied with one's weight as an aspect of the assessment of one's appearance (Dunn post hoc analysis: $p<0.001)$. Health, understood as an aspect of one's attitude one's own body, was assessed the highest by women with psoriasis (post hoc Tukey: $p=0.01$ ). 
TABLE 2 | Differences in the assessments of one's body (MBSRQ) between the groups.

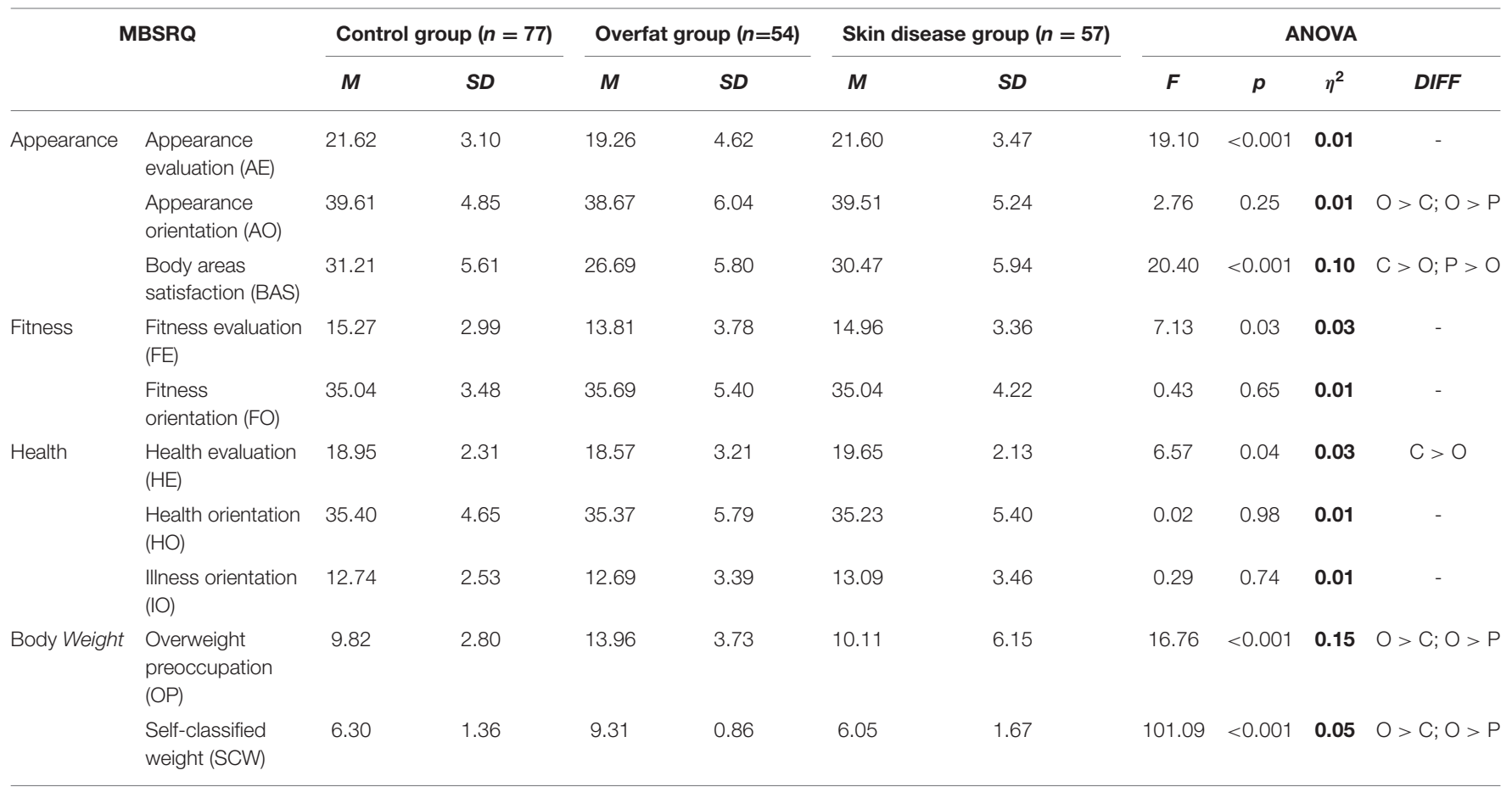

C, Control Group; O, Women with obesity; P, Women with Psoriasis; $\eta^{2}$, magnitude of effect.

TABLE 3 | Differences in perceived stigma between the groups.

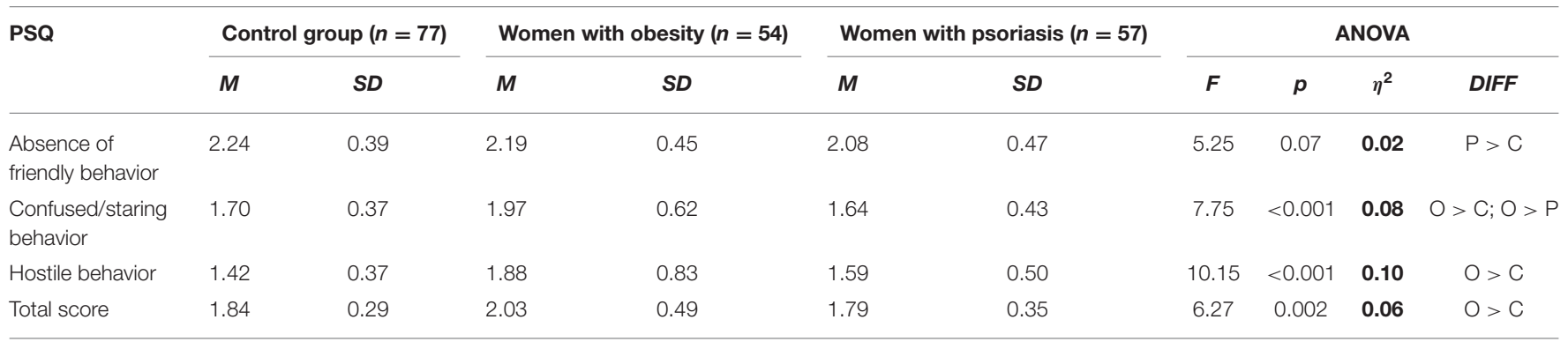

C, Control Group; O, Women with obesity; P, Women with Psoriasis; $\eta^{2}$, magnitude of effect.

Some statistically significant differences were also observed for perceived stigma (Table 3).

Overall sense of stigma was greater in women affected by obesity than those affected by psoriasis $(p=0.012)$ or the control group $(p=0.044)$. Further analyses did not reveal any differences between women with psoriasis and women from the control group $(p=0.493)$.

\section{Objective Body Dimensions and Perceived Stigma}

In the next step, we investigated the relationships of anthropometric indices and body dimension with perceived stigma. There was a surprising lack of relationship between perceived stigma and objective indices regarding body shape (WHR, ICO) as well as the severity of psoriasis (Disease Severity). However, there were correlations between sense of stigma and parameters associated with body mass and fat levels (Table 4).
The greatest number of significant correlations were observed in the group of women affected by obesity. Interestingly, significant relationships revealed in the psoriasis group were negative, which means that the higher one's body mass, the lesser the perceived stigma (provided one does not reach the threshold of being overweight).

\section{Moderating Role of the Body Image for Perceived Stigma}

Moderation analysis was performed in order to investigate the role of subjective assessment of one's body in the relation between objective body measurements and perceived stigma (Figure 1).

No moderation effect was observed in the relation between objective indices regarding body shape (WHR and ICO) as well as the severity of psoriasis (Disease Severity) and perceived stigma. Health Evaluation was the most common moderator associated with the subjective attitude towards one's own body 
in the relationship between body dimensions (body mass, $\% \mathrm{BF}$, and visceral fat) and perceived stigma. It is worth noting that this was the only moderating factor in the group of women with psoriasis, while it did not moderate any of the relationships in the case of women with obesity. Interestingly, in the group of

TABLE 4 | Correlation between body dimension and perceived stigma.

\begin{tabular}{|c|c|c|c|c|}
\hline \multirow[b]{2}{*}{ PSQ } & \multirow[b]{2}{*}{ Group } & \multicolumn{3}{|c|}{ Body dimension } \\
\hline & & Body mass & $\% B F$ & Visceral fat \\
\hline \multirow{3}{*}{$\begin{array}{l}\text { Absence of } \\
\text { friendly } \\
\text { behavior }\end{array}$} & Control group $(n=77)$ & $-0.22^{\star}$ & $-0.31^{\star \star}$ & -0.16 \\
\hline & $\begin{array}{l}\text { Women with obesity } \\
(n=54)\end{array}$ & 0.06 & 0.10 & 0.08 \\
\hline & $\begin{array}{l}\text { Women with psoriasis } \\
(n=57)\end{array}$ & -0.24 & -0.24 & -0.05 \\
\hline \multirow{3}{*}{$\begin{array}{l}\text { Confused/ } \\
\text { staring } \\
\text { behavior }\end{array}$} & $\begin{array}{l}\text { Control group } \\
(n=77)\end{array}$ & -0.07 & $-0.29^{\star \star}$ & $-0.30^{\star \star}$ \\
\hline & $\begin{array}{l}\text { Women with obesity } \\
(n=54)\end{array}$ & $0.40^{\star \star}$ & $0.33^{\star}$ & $0.39^{\star \star}$ \\
\hline & $\begin{array}{l}\text { Women with psoriasis } \\
(n=57)\end{array}$ & 0.02 & -0.08 & 0.16 \\
\hline \multirow[t]{3}{*}{$\begin{array}{l}\text { Hostile } \\
\text { behavior }\end{array}$} & $\begin{array}{l}\text { Control group } \\
(n=77)\end{array}$ & -0.22 & $-0.24^{*}$ & -0.12 \\
\hline & $\begin{array}{l}\text { Women with obesity } \\
(n=54)\end{array}$ & $0.48^{\star \star \star}$ & $0.39^{\star \star}$ & $0.36^{\star \star}$ \\
\hline & $\begin{array}{l}\text { Women with psoriasis } \\
(n=57)\end{array}$ & $-0.31^{\star}$ & -0.18 & 0.00 \\
\hline \multirow[t]{3}{*}{ Total score } & $\begin{array}{l}\text { Control Group } \\
(n=77)\end{array}$ & -0.22 & $-0.37^{\star \star \star}$ & $-0.27^{*}$ \\
\hline & $\begin{array}{l}\text { Women with obesity } \\
(n=54)\end{array}$ & $0.41^{\star \star}$ & $0.35^{\star \star}$ & $0.36^{\star \star}$ \\
\hline & $\begin{array}{l}\text { Women with psoriasis } \\
(n=57)\end{array}$ & -0.21 & -0.22 & 0.04 \\
\hline
\end{tabular}

$p<0.001,{ }^{* *} p<0.01,{ }^{*} p<0.05$. women affected with obesity, attitude towards one's own body significantly influenced the sense of being stared at and the experience of hostile behaviours in social relations when body mass or body fat levels were higher.

\section{DISCUSSION}

The main objective of this research was to verify the subjective role of the assessment of one's body in the relationship between objective indices of appearance and the perceived stigma among young women. The above-presented analyses largely supported the hypotheses.

\section{Sense of Stigma Among Young Women With Conditions That Decrease One's Physical Attractiveness}

We hypothesised that the level of perceived stigma would depend on the type of stigma. The fact of being chronically ill itself, irrespective of the type of illness, results in stigma (73). However, our study found that not every illness leads to the same levels of perceived stigma. In line with the hypotheses, obese women were more likely to have a sense of stigma than women in other groups. This agrees with our previous results: a study on a smaller number of women (11) found that obese women were more likely to experience hostility as part of their stigma than women with skin conditions or those without an objective stigma. Lin et al. (74) asked 464 teenagers who were either overweight or nonobese about depressive symptoms, perceived stigma associated with body mass, and internalised stigma; they also measured actual and perceived weight status. They concluded that weightrelated self-stigma is a problem even for people who are not overweight, because perceived weight stigma was associated with weight-related self-stigma regardless of body mass status. Strong associations between perceived weight stigma and weight-related self-stigma have been observed. In a study by Vartanian et al. (75), with 598 participants, pictures of women who were either obese

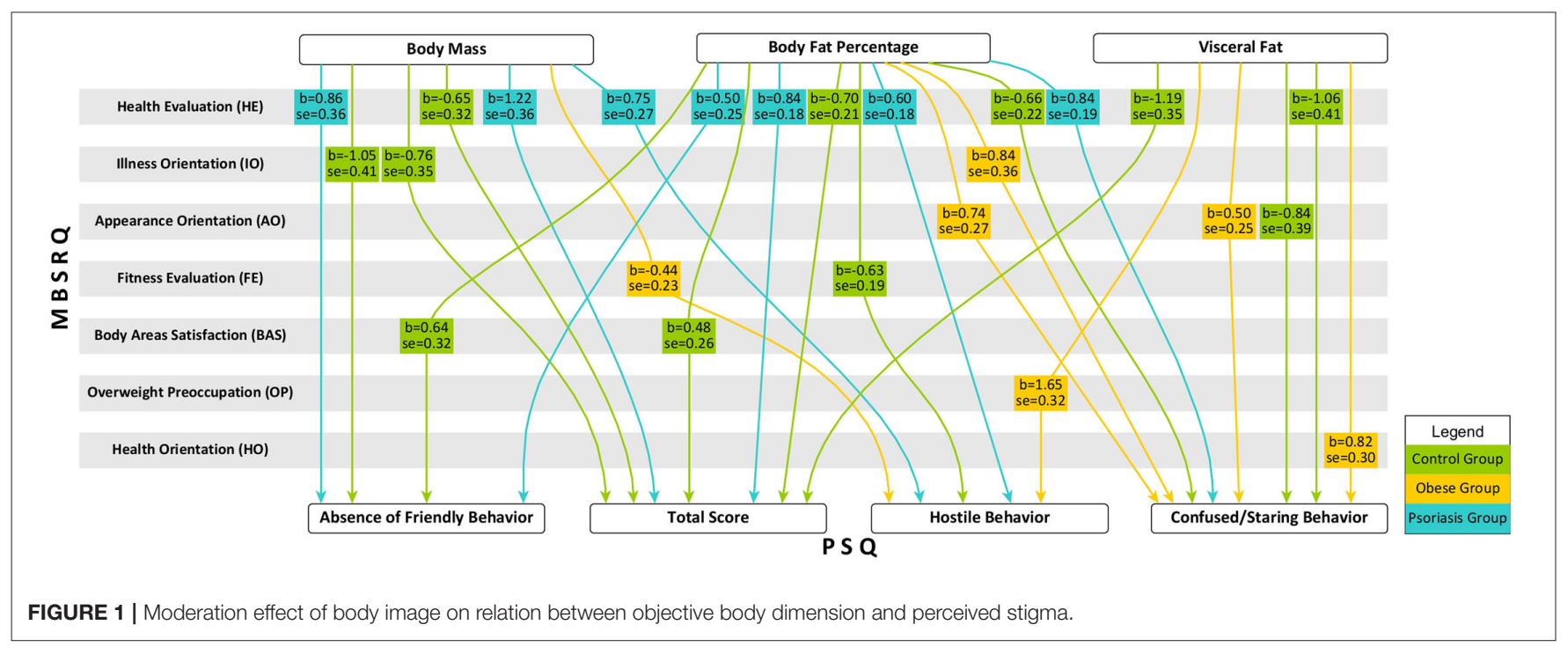


or non-obese were shown to the participants, who assessed them with regards to emotions, attitudes, stereotypes, or desire for social distance. Images of obese individuals inspired more disgust and negative attitudes and stereotypes as well as greater desire for social distance. The researchers concluded that disgust plays an important role in prejudices and discrimination towards obese individuals and that it may partially explain prejudice against overweight people.

We also hypothesised that women affected with psoriasis would differ from the control group in terms of their perceived stigma; however, this hypothesis was not supported by the collected data. Moreover, the severity of the disease, its phase, and the size of affected skin surface also did not impact levels of perceived stigma. This is in line with the research by Rzeszutek et al. (76), which showed that some people affected by psoriasis do not differ in their attitudes from healthy individuals. Moreover, higher satisfaction with their own body and resources allows individuals with psoriasis levels of life satisfaction similar to those of the general population This is also in line with the research by Sakson-Obada and Wycisk (77), who found that accepting one's illness and positive body image and body experiences decreased the negative impact of psoriasis. Thus, positive body image may also facilitate more successful coping with physical symptoms of psoriasis and increase the well-being of patients (78), thereby decreasing perceived stigma.

Interestingly, women who were not overweight and did not suffer from any skin condition, even those with high body fat levels, did not perceive a lack of positive behaviours towards them or lack of compliments. This is in line with previous research (79) that found that women who were not overweight did not associate increased body mass or body fat with lack of friendly behaviours towards them. Contrasting results were observed by Lipowska et al. (33), where lack of perceived friendly behaviours was deemed an important component of stigma and compliments played an important role in building the body esteem of the young female participants, independently of their body mass.

\section{The Role of Attitudes Towards One's Body in the Relationship Between Objective Body Measurements and Perceived Stigma}

We hypothesised that the attitude towards one's body would be a moderator of the relationship between the objective parameters of the stigmatising illness and perceived stigma. Attitudes towards one's body are developed from the earliest years of life, starting with the stage of getting to know one's own body. After that, these attitudes are shaped and internalised through comparisons with people around us, their opinions, and attitudes towards us. For girls and women, body image comprises a much bigger part of the "self" than is the case for men, and it strongly influences their overall self-esteem $(35,36)$. From the earliest years of life, women experience stigma and negative judgements associated with increased body mass. One study on a group of children aged 3 to 7 (80) in which participants were asked to describe their preferences for the appearance of playmates as well as to ascribe features attributed to normal and overweight figures revealed that girls are more strict in their judgements of overweight individuals than boys. As per Carof's report (81), despite the fact that European countries vary in their cultures' approaches to overfat and obesity, attitudes towards excess body mass are generally negative and are also often associated with moral judgements of the individual. This is why it is worth emphasising that our results indicate that body mass and its components (fat percentage and visceral fat) play an important role in the relationship with one's own body and perceived stigma. Independently of the objective stigma and body shape (proportions), preoccupation with one's body mass and control over it is a factor that influences one's body image and perceived stigma. Moreover, preoccupation with one's appearance was stronger in the group of obese women than in the remaining groups, and it played an important role in the relationship between objective body dimensions (body fat, visceral fat) and the sense of being stared at because of one's appearance. It can be thus supposed that weight is an important factor in determining to what extent a woman feels attractive, what attitudes she has towards her own body, and whether she perceives weight-related stigma. This is in line with the research of Tovée et al. (82), according to whom body weight explained as much as $53 \%$ of the variance in attractiveness among women, while in the case of men it was only $13 \%$. Interestingly, according to the Faries and Bartholomew (83) study, fat percentage seems to be a strong indicator of attractiveness, and the influence of WHR and BMI on attractiveness is partially dependent on it. Despite the fact that multiple studies indicate that women are more preoccupied with their weight than are men (84) and women with higher body mass are more dissatisfied with their appearance (85-87), dissatisfaction with one's appearance and body mass appears to be a universal phenomenon for women (88). Similar results were observed in a study in which all female participants, independently of their body mass and body fat levels, expressed dissatisfaction with their body mass and a desire to reduce it (79). Interestingly, in the study Blodorn et al. (89), women with higher weight, when they were to describe during the study why they would make a good date, and their potential partner would see or hear their recording, felt greater expectations of social rejection when weight was seen (vs. unseen). Experimental studies (90) additionally revealed that showing women who are initially dissatisfied with their bodies images of a very slim "perfect" body significantly increased their levels of dissatisfaction, and led them to judge themselves more harshly. This effect was not observed in women who were initially satisfied with their bodies. Body weight is therefore one of the strongest predictors of satisfaction with one's appearance in women - the lowest level of satisfaction is shown by people with the highest body mass (91).

Moreover, our analyses did not support the existence of a relationship between parameters related to body shape and perceived stigma when the subjective assessment of one's body was tested as a moderator of this relationship. Similar results were observed for a group of Polish and Vietnamese young people (33), for whom objective body measurements did not influence sense of stigma among women. No relationship between anthropometric indices and assessment of one's own body was observed and waist to hip ratio was associated with 
one's satisfaction with body mass and physical fitness. Moreover, in Polish women, BMI had little influence over assessment of their bodies. This again supports the claim that body mass and its components, and not body shape, influences our attitudes towards our own bodies, and whether we perceive stigma related to our appearance.

A surprising result of the presented study was the positive assessment of one's own health by women affected with psoriasis. This positive assessment seems to lower the levels of perceived stigma, even when body mass or body fat levels are higher. This is in line with the results of a study by AlexandrovaKaramanova (92), who found that young people who assessed their health positively also exhibited more positive feelings and attitudes towards their bodies and appearance. This is even more surprising because psoriasis significantly impacts one's sense of physical attractiveness and acceptance of one's own body (77). A completely different approach towards one's own body and stigma was revealed in the case of obese women. It is likely that women do not treat obesity as an illness per se. Obesity is associated with a number of consequences for one's physical health (93-95); however, these medical conditions are often not directly associated with obesity (in the sense that people not affected by obesity also suffer from these conditions). Thus, it is possible that an individual does not perceive such diseases as associated with obesity, but rather as conditions independent of their appearance, which is why they assess their health differently and pay less attention to the evaluation thereof in the context of their appearance or stigma. Skin conditions require treatment on many levels, such as taking good care of one's skin, alleviating itchiness, regular visits to a specialist, and concealing the affected areas $(96,97)$. In the case of psoriasis, believing that one has internal control over one's health is associated with the acceptance of the condition, which facilitates adherence to guidelines given by specialists, which, in turn, allows for relatively successful treatment of symptoms (98). Thus, a positive assessment of one's health may allow one to better cope with the physical symptoms of psoriasis and helps reduce stress (which exacerbates the condition) (99).

\section{CONCLUSION}

Summing up, the main conclusion of our study is the fact that subjective assessment of one's body and attitudes towards one's body influence perceived stigma, independently of objective body shape or the type of condition causing the stigma. At the same time, body mass is a strong predictor of perceived stigma for all women.

Levels of perceived stigma differ between women with psoriasis and women affected by obesity. Obese women feel stigmatised more strongly than the rest of the group. Patients suffering from psoriasis assessed their health as most inportnant element of body evaluation, which may result in a lower sense of stigmatisation in this group. Therefore, perceived stigma should be taken into account when working with obese individuals and actions could be taken to help improve their body image. Furthermore, social programmes should take the necessary steps to reduce stigma related to body mass, through prophylaxis in the field of health, sugar and lipid economy, physical activity as well as psychological and medical support. When working with stigmatised women, it is also worth focusing on their resources and skills, which will increase their self-esteem and self-efficacy. At the same time, as long as the media portrays very slim female bodies with smooth skin as desirable, comparing one's own body to that model will lower body satisfaction and foster eating disorders.

\section{LIMITATIONS}

Our research involved young women who are particularly vulnerable to social disapproval and criticism for having an unattractive appearance and appearance that does not meet age norms. Moreover, as we mentioned, body image is a much more important element of "Self" for girls and women than for men. At the same time, it would be worthwhile to also study young men affected by obesity and psoriasis in order to assess the role that gender plays in these phenomena. This will broaden our understanding of the role of body image in the sense of stigma in those affected by appearance-related diseases. Another limitation is related to the selection of participants based on just two medical conditions: it is possible that extending the study to other visible conditions that may cause stigma could reveal more general tendencies regarding the relationship between one's body, attitudes towards one's body, and perceived stigma.

The sample size is another limitation of our study. Despite the fact that both excess body mass and skin conditions affect a large number of women, not all the women who were invited to take part in the study agreed to the collection of anthropometric data (e.g., stepping on the scale). Therefore, the results of our study cannot be generalised to all women with obesity and psoriasis. The sample size also limits the number and depth of analyses that could be conducted. While we can correlate anthropometric variables with sense of stigma, a longitudinal study would allow us to better determine causality. It would be worthwhile to extend the study to see whether similar results can be observed in a bigger sample. The way that participants were recruited (deliberate sample selection) may also be a limitation. Moreover, place of residence, marital status, and parental status were not taken into account in the study, thereby limiting the possible analyses. It may be that pregnancy or place of residence influence the perceived stigma or the attention paid to particular body imperfections.

\section{DATA AVAILABILITY STATEMENT}

The raw data supporting the conclusions of this article will be made available by the authors, without undue reservation.

\section{ETHICS STATEMENT}

The studies involving human participants were reviewed and approved by the Ethics Board for Research Projects at the Institute of Psychology, University of Gdansk, Poland (decision 
no. 12/2018). Written informed consent for participation was not required for this study in accordance with the national legislation and the institutional requirements.

\section{AUTHOR CONTRIBUTIONS}

NM and ML: conceptualisation, methodology, writing-original draft preparation, and writing-review and editing. JK: software and validation. JK and ML: formal analysis. NM: investigation,

\section{REFERENCES}

1. Cash T. Cognitive-behavioral perspectives on body image. In: Thomas C, Pruzinsky T, editors. Body Image. A Handbook of Theory, Research and Clinical Practice. New York, NY: The Guilford Press (2002). p. 478-86.

2. Grilo CM, Crosby RD, Machado PPP. Examining the distinctiveness of body image concerns in patients with anorexia nervosa and bulimia nervosa. Int $J$ Eat Disord. (2019) 52:1229-36. doi: 10.1002/eat.23161

3. Wojtyła-Buciora P, Klimberg A, Wojtyła A, Katedra, Fizjologii Z, Marcinkowskiego. Społecznej K. Samoocena własnej sylwetki a wskaznik masy ciała młodziezy w Polsce Self-rating of body shape vs. body mass index in Polish youth. Probl Hig Epidemiol. (2018) 99:146-54.

4. Davison TE, McCabe MP. Adolescent body image and psychosocial functioning. J Soc Psychol. (2006) 146:15-30. doi: 10.3200/SOCP.146.1.15-30

5. Williams JM, Currie C. Self-esteem and physical development in early adolescence: pubertal timing and body image. J Early Adolesc. (2000) 20:12949. doi: $10.1177 / 0272431600020002002$

6. Datta Gupta N, Etcoff NL, Jaeger MM. Beauty in mind: the effects of physical attractiveness on psychological well-being and distress. J Happiness Stud. (2016) 17:1313-25. doi: 10.1007/s10902-015-9644-6

7. Kim YA. Emotional evidence: influences on happiness from the frequent positive visual exposure. In: International Conference on Applied Human Factors and Ergonomics. Washington, DC (2018)

8. Ossowski R. Psychologiczne problemy w redukcji wagi ciała. In: Przemysław Paweł Grzybowski BK, editor. Seniorzy w działaniu: stuchacze Kazimierzowskiego Uniwersytetu Trzeciego Wieku i działalność wolontaryjna. Fundacja dla Uniwersytetu Kazimierza Wielkiego, Bydgoszcz (2013). p. 60-9.

9. Westfall RS, Millar MG, Lovitt A. The Influence of physical attractiveness on belief in a just world. Psychol Rep. (2019) 122:536-49. doi: 10.1177/0033294118763172

10. Chang S-R, Yang CF, Chen K-H. Relationships between body image, sexual dysfunction, and health-related quality of life among middleaged women: a cross-sectional study [Article]. Maturitas. (2019) 126:4550. doi: $10.1016 /$ j.maturitas.2019.04.218

11. Lipowska M, Bidzan M, Mazurkiewicz N, Lipowski M. Jakość zycia w przewlekłej widocznej chorobie a poczucie stygmatyzacji u młodych kobiet [Quality of life chronic visible illness and the sense of stigmatization in young women]. Przeglad Psychologiczny. (2015) 58:303-23.

12. Sola M, Gajewska E, Manikowski W. Wpływ otyłości na jakość zycia zwiazana ze stanem zdrowia wśród dziewczat i chłopców. Nowiny Lekarskie. (2012) 81:321-9.

13. Bucchianeri MM, Arikian AJ, Hannan PJ, Eisenberg ME, NeumarkSztainer D. Body dissatisfaction from adolescence to young adulthood: findings from a 10-year longitudinal study. Body Image. (2013) 10:17. doi: $10.1016 /$ j.bodyim. 2012.09 .001

14. Mitchell SH, Petrie TA, Greenleaf CA, Martin SB. Moderators of the internalization-body dissatisfaction relationship in middle school girls. Body Image. (2012) 9:431-40. doi: 10.1016/j.bodyim.2012.07.001

15. Suelter CS, Schvey N, Kelly NR, Shanks M, Thompson KA, Mehari R, et al. Relationship of pressure to be thin with gains in body weight and fat mass in adolescents. Pediatric Obesity. (2018) 13:14-22. doi: 10.1111/ijpo.12179

16. Izydorczyk BC, Raba M, Sitnik-Warchulska K. Resilience, self-esteem, and body attitude in women from early to late adulthood. Health Psychol Rep. (2018) 6:193-206. doi: 10.5114/hpr.2018.74698 data curation, and project administration. ML: supervision and funding acquisition. All authors contributed to the article and approved the submitted version.

\section{FUNDING}

The work of ML was supported by grant 2015/17/B/HS6/04144 from the National Science Centre, Poland; the University of Gdansk covered the costs of open access publishing.

17. Bellard A, Urgesi C, Cazzato V. Self-body recognition and attitudes towards body image in younger and older women. Arch Womens Mental Health. (2021) doi: 10.1007/s00737-021-01164-x. [Epub ahead of print].

18. Ferraro F, Muehlenkamp J, Paintner A, Wasson K, Hager T, Hoverson F. Aging, body image, body shape. J Gen Psychol. (2008) 135:37992. doi: 10.3200/GENP.135.4.379-392

19. Gestsdottir S, Svansdottir E, Sigurdsson H, Arnarsson A, Ommundsen Y, Arngrimsson S, et al. Different factors associate with body image in adolescence than in emerging adulthood: A gender comparison in a follow-up study. Health Psychol Rep. (2018) 6:81-93. doi: 10.5114/hpr.2018.71201

20. Puhl RM, Lessard LM. Weight stigma in youth: prevalence, consequences, and considerations for clinical practice. Curr Obes Rep. (2020) 9:40211. doi: 10.1007/s13679-020-00408-8

21. Tuszyńska-Bogucka W, Bogucki J. Slim, smart and happy? Stigmatization of obesity among preschool children. Przeglad Badań Edukacyjnych, (2016) 1:7. doi: 10.12775/PBE.2015.058

22. Cash TF. Multidimensional body-self relations questionnaire (MBSRQ). In: Wade T, editor. Encyclopedia of Feeding and Eating Disorders. Singapore: Springer (2017). p. 551-555.

23. Thompson JK, van den Berg P, Roehrig M, Guarda AS, Heinberg LJ. The sociocultural attitudes towards appearance scale-3 (SATAQ-3): development and validation. Int J Eat Disord. (2004) 35:293-304. doi: 10.1002/eat.10257

24. Chisuwa N, O'Dea JA. Body image and eating disorders amongst Japanese adolescents. A review of the literature. Appetite. (2010) 54:515. doi: 10.1016/j.appet.2009.11.008

25. Jill Thompson A, Poyrazli S, Miller E. Western media and body image dissatisfaction in young women in developing nations. Eur J Educ Res. (2020) 90:45-66. doi: 10.14689/ejer.2020.90.3

26. Dixson B, Li B, Dixson A. Female waist-to-hip ratio, body mass index and sexual attractiveness in China. Curr Zool. (2010) 56:17581. doi: 10.1093/czoolo/56.2.175

27. Harrison K. Television viewers' ideal body proportions: the case of the curvaceously thin woman. Sex Roles. (2003) 48:25564. doi: 10.1023/A:1022825421647

28. Coy AE, Green JD, Price ME. Why is low waist-to-chest ratio attractive in males? The mediating roles of perceived dominance, fitness, protection ability. Body Image. (2014) 11:282-9. doi: 10.1016/j.bodyim.2014.04.003

29. Knauss C, Paxton SJ, Alsaker FD. Relationships amongst body dissatisfaction, internalisation of the media body ideal and perceived pressure from media in adolescent girls and boys. Body Image. (2007) 4:353-60. doi: 10.1016/j.bodyim.2007.06.007

30. Cash TF, Henry PE. Women's body images: The results of a national survey in the U.S.A. Sex Roles. (1995) 33:19-28. doi: 10.1007/BF015 47933

31. Czepczor-Bernat K, Kościcka K, Brytek-Matera A. Społeczno-kulturowe postawy wobec własnego wygladu i niezadowolenie $\mathrm{z}$ ciała $\mathrm{u}$ kobiet $\mathrm{i}$ mezczyzn w okresie póznej adolescencji: badania wstepne [The Sociocultural Attitudes Towards Appearance And Body Dissatisfaction Among Late Adolescence: a Pilot Study]. Polskie Forum Psychologiczne. (2016) 21:364-77. doi: 10.14656/PFP20160303

32. Izydorczyk B, Truong Thi Khanh H, Lizińczyk S, Sitnik-Warchulska K, Lipowska M, Gulbicka A. Body dissatisfaction, restrictive, and bulimic behaviours among young women: a polish-Japanese comparison. Nutrients. (2020) 12:666. doi: 10.3390/nu12030666 
33. Lipowska M, Truong Thi Khanh H, Lipowski M, Rózycka-Tran J, Bidzan M, Ha TT. The Body as an object of stigmatization in cultures of guilt and shame: a polish-Vietnamese comparison. Int J Environ Res Public Health. (2019) 16:2814. doi: 10.3390/ijerph16162814

34. Franzoi SL, Vasquez K, Sparapani E, Frost K, Martin J, Aebly M. Exploring body comparison tendencies: women are self-critical whereas men are self-hopeful. Psychol Women Quart. (2012) 36:99-109. doi: 10.1177/0361684311427028

35. Lipowska M, Lipowski M. Narcissism as a moderator of satisfaction with body image in young women with extreme underweight and obesity. PLOS ONE. (2015) 10:e0126724. doi: 10.1371/journal.pone.0126724

36. Tiggemann M, McCourt A. Body appreciation in adult women: relationships with age and body satisfaction. Body Image. (2013) 10:624-7. doi: 10.1016/j.bodyim.2013.07.003

37. Muth JL, Cash TF. Body-image attitudes: what difference does gender make?.J Appl Soc Psychol. (1997) 27:1438-52. doi: 10.1111/j.1559-1816.1997.tb01607.x

38. Lammers WJ, Davis S, Davidson O, Hogue K. Impact of positive, negative, and no personality descriptors on the attractiveness halo effect. Psi Chi J Psychol Res. (2016) 21:29-34. doi: 10.24839/2164-8204.JN21.1.29

39. Eagly AH, Ashmore RD, Makhijani MG, Longo LC. What is beautiful is good, but...: A meta-analytic review of research on the physical attractiveness stereotype. Psychol Bull. (1991) 110:109-28. doi: 10.1037/0033-2909.110.1.109

40. Leary M. Wywieranie wrazenia na innych, o sztuce prezentacji. Gdańsk, GWP (2004)

41. Xu M. Analysis on the Influence of Female Characters in Disney Films. In: 2021 th International Seminar on Education, Management and Social Sciences (ISEMSS 2021). Chengdu (2021).

42. Izydorczyk B. Psychoterapia zaburzeń obrazu ciała w anoreksji i bulimii psychicznej: podejście integracyjne (zastosowanie terapii psychodynamicznej i technik psychodramy). Psychoterapia. (2017) 1:5-22.

43. Phillips KA. Body dysmorphic disorder: recognizing and treating imagined ugliness. World Psychiatry. (2004) 3:12-7.

44. Turner C, Cadman J. When adolescents feel ugly: cognitive behavioral therapy for body dysmorphic disorder in youth. J Cogn Psychother. (2017) 31:24254. doi: 10.1891/0889-8391.31.4.242

45. Rosińska M, Rzepa T, Szramka-Pawlak B, Zaba R. Body image and depressive symptoms in person suffering from psoriasis. Psychiatr Pol. (2017) 51:114552. doi: $10.12740 / \mathrm{PP} / 68948$

46. Rzeszutek M, Schier K. Tak bolesne, ze az obce? - Zwiazek pomiedzy depresja a obrazem ciała u młodych dorostych. Psychoterapia. (2008) 4:5-16.

47. Emmer C, Bosnjak M, Mata J. The association between weight stigma and mental health: a meta-analysis. Obes Rev. (2020) 21:e12935. doi: 10.1111/obr.12935

48. Izydorczyk B, Truong Thi Khanh H, Lipowska M, Sitnik-Warchulska K, Lizińczyk S. Psychological risk factors for the development of restrictive and bulimic eating behaviors: a polish and vietnamese comparison. Nutrients. (2021) 13:910. doi: 10.3390/nu13030910

49. Dovidio JF, Crocker J. Pietno: wprowadzenie i zarys ogólny. In: Heatherton TF, Kleck RE, Hebl MR, Hull JG, editors. Społeczna psychologia pietna. Wydawnictwo Naukowe PWN (2008). p. 23-46.

50. Goffman E. Stigma; Notes on the Management of Spoiled Identity. Englewood Cliffs, NJ: Prentice-Hall (1963).

51. Chaudoir SR, Earnshaw VA, Andel S. Discredited versus discreditable: understanding how shared and unique stigma mechanisms affect psychological and physical health disparities. Basic Appl Soc Psychol. (2013) 35:75-87. doi: 10.1080/01973533.2012.746612

52. Czykwin E. Stygmat społeczny. Warszawa: Wydawnictwo Naukowe PWN (2007).

53. Zhang M, Barreto M, Doyle D. Stigma-based rejection experiences affect trust in others. Soc Psychol Pers Sci. (2020) 11:30816. doi: $10.1177 / 1948550619829057$

54. BeugEn S, MiddEndorp H, Ferwerda M, Smit JV, ZeeuwEn - FranssEn MEJ, Kroft EBM, et al. Predictors of perceived stigmatization in patients with psoriasis. Br J Dermatol. (2017) 176:687-94. doi: 10.1111/bjd.14875

55. Dalgard FJ, Bewley A, Evers AW, Gieler U, Lien L, Sampogna F, et al. Stigmatisation and body image impairment in dermatological patients: protocol for an observational multicentre study in 16 European countries. BMJ Open. (2018) 8:e024877. doi: 10.1136/bmjopen-2018-024877
56. Godoy-Izquierdo D, González-Hernández J, Rodríguez-Tadeo A, Lara R, Ogallar A, Navarrón E., et al. Body satisfaction, weight stigma, positivity, and happiness among Spanish adults with overweight and obesity. Int J Environ Res Public Health. (2020) 17:4186. doi: 10.3390/ijerph17124186

57. Miniszewska J, Chodkiewicz J, Ograczyk-Piotrowska A, Zalewska-Janowska A. Life satisfaction and health related quality of life - the same or a different construct? A survey in psoriasis patients. Health Psychol Rep. (2020) 8:21927. doi: 10.5114/hpr.2020.95909

58. Ograczyk A, Miniszewska J, Kepska A, Zalewska-Janowska A. Itch, disease coping strategies and quality of life in psoriasis patients. Postepy Dermatologii i Alergologii. (2014) 31:299-304. doi: 10.5114/pdia.2014.40927

59. Capon F. The genetic basis of psoriasis. Int J Mol Sci. (2017) 18:2526. doi: $10.3390 /$ ijms 18122526

60. DeStefano GM, Christiano AM. The genetics of human skin disease. Cold Spring Harbor perspect Med. (2014) 4:a015172. doi: 10.1101/cshperspect.a015172

61. WHO. Obesity and Overweight. (2021). World Health Organization. Available online at: www.who.int/en/news-room/fact-sheets/detail/obesity-and-overweight (accessed January 10, 2021).

62. Al-Mutairi N, Nour T. The effect of weight reduction on treatment outcomes in obese patients with psoriasis on biologic therapy: a randomized controlled prospective trial. Expert Opin Biol Ther. (2014) 14:749-56. doi: 10.1517/14712598.2014.900541

63. Lipowska M, Lipowski M, Jurek P, Jankowska AM, Pawlicka P. Gender and body-fat status as predictors of parental feeding styles and children's nutritional knowledge, eating habits and behaviours. Int J Environ Res Public Health. (2018) 15:852. doi: 10.3390/ijerph15050852

64. Leighton K, Kardong-Edgren S, Schneidereith T, Foisy-Doll C. Using social media and snowball sampling as an alternative recruitment strategy for research. Clin Simulat Nurs. (2021) 55:37-42. doi: 10.1016/j.ecns.2021.03.006

65. Cash T. The Multidimensional Body-Self Relations Questionnaire. MB-SRQ Users' Manual. VA Vol. 3. Norfolk: Old Dominion University (2000).

66. Brytek-Matera A, Rogoza R. Validation of the polish version of the multidimensional body-self relations questionnaire among women. Eating Weight Disord. (2015) 20:109-17. doi: 10.1007/s40519-014-0156-х

67. Lawrence JW, Fauerbach JA, Heinberg LJ, Doctor M, Thombs BD. The reliability and validity of the Perceived Stigmatization Questionnaire (PSQ) and the Social Comfort Questionnaire (SCQ) among an adult burn survivor sample. Psychol Assess. (2006) 18:106-11. doi: 10.1037/1040-3590.18.1.106

68. Elffers TW, de Mutsert R, Lamb HJ, de Roos A, Willems van Dijk K, Rosendaal FR, et al. Body fat distribution, in particular visceral fat, is associated with cardiometabolic risk factors in obese women. PLoS ONE. (2017) 12:e0185403. doi: 10.1371/journal.pone. 0185403

69. Sweeting HN. Measurement and definitions of obesity in childhood and adolescence: a field guide for the uninitiated. Nutr J. (2007) 6:32. doi: 10.1186/1475-2891-6-32

70. Maffetone PB, Rivera-Dominguez I, Laursen PB. Overfat and underfat: new terms and definitions long overdue [hypothesis and theory]. Front Public Health. (2017) 4:279. doi: 10.3389/fpubh.2016.00279

71. Parikh R, Mohan V, Joshi S. Should waist circumference be replaced by index of central obesity (ICO) in definition of metabolic syndrome? Diab/Metab Res Rev. (2012) 28:3-5. doi: 10.1002/dmrr.1227

72. Pawłowski B, Dunbar RI. Waist-to-hip ratio versus body mass index as predictors of fitness in women. Hum Nat. (2005) 16:164-77. doi: 10.1007/s12110-005-1002-7

73. Markiewicz A, Gryglicka H, Hozyasz KK. Napietnowanie społeczne w chorobach przewlekłych. Pediatria Polska. (2017) 92:316-20. doi: 10.1016/j.pepo.2016.11.005

74. Lin C-Y, Tsai M-C, Liu C-H, Hsieh Y-P, Strong C. Psychological pathway from obesity-related stigma to anxiety via internalized stigma and selfesteem among adolescents in Taiwan. Int J Environ Res Public Health. (2019) 16:4410.. doi: 10.3390/ijerph16224410

75. Vartanian LR, Trewartha T, Vanman EJ. Disgust predicts prejudice and discrimination toward individuals with obesity. J Appl Soc Psychol. (2016) 6:369. doi: $10.1111 /$ jasp. 12370

76. Rzeszutek M, Podkowa Pieta M, Pankowski D, Cyran-Stemplewska S. Comparative study of life satisfaction among patients with psoriasis versus 
healthy comparison group: the explanatory role of body image and resource profiles. Qual Life Res. (2021) 30:181-91. doi: 10.1007/s11136-02002621-3

77. Sakson-Obada O, Wycisk J. Łuszczyca jako czynnik ryzyka dla zakłóceń w ja cielesnym-moderujaca rola płci. Polskie Forum Psychol. (2017). 22:459-77. doi: 10.14656/PFP20170307

78. Gündüz A, Topçuoglu V, Usta Gündüz EB, Ergun T, Gencosmanoglu DS, Sungur MZ. Significant effects of body image on sexual functions and satisfaction in psoriasis patients. J Sex Marital Ther. (2020) 46:1609. doi: 10.1080/0092623X.2019.1654582

79. Mazurkiewicz N, Lipowski M, Krefta J, Lipowska M. Better if they laugh with me than at me: the role of humor in coping with obesityrelated stigma in women. Int J Environ Res Public Health. (2021) 18:7974. doi: 10.3390/ijerph18157974

80. Jenull B, Mayer C, Knobel P, Birnbacher R. Weight-Stigma and Body Satisfaction among Preschool Children. J Pediatr Perinatol Child Health. (2021). 5:112-25. doi: 10.26502/jppch.74050069

81. Carof S. Is there a National body? How national cultures shape the 'fat' body and the food practices. Stud Ethnic National. (2017) 17:5767. doi: 10.1111/sena.12219

82. Tovée MJ, Maisey DS, Vale EL, Cornelissen PL. Characteristics of male attractiveness for women. Lancet. (1999) 353:1500. doi: 10.1016/S0140-6736(99)00438-9

83. Faries MD, Bartholomew JB. The role of body fat in female attractiveness. Evolut Hum Behav. (2012) 33:67281. doi: 10.1016/j.evolhumbehav.2012.05.002

84. Bibiloni MdM, Coll JL, Pich J, Pons A, Tur JA. Body image satisfaction and weight concerns among a Mediterranean adult population. BMC Public Health. (2017) 17:39. doi: 10.1186/s12889-016-3919-7

85. Annis NM, Cash TF, Hrabosky JI. Body image and psychosocial differences among stable average weight, currently overweight, and formerly overweight women: the role of stigmatizing experiences. Body Image. (2004) 1:15567. doi: 10.1016/j.bodyim.2003.12.001

86. Radwan H, Hasan HA, Ismat H, Hakim H, Khalid H, Al-Fityani L, et al. Body mass index perception, body image dissatisfaction and their relations with weight-related behaviors among University Students. Int J Environ Res Public Health. (2019) 16:9. doi: 10.3390/ijerph16091541

87. Siervo M, Montagnese C, Muscariello E, Evans E, Stephan B, Nasti $\mathrm{G}$, et al. Weight loss expectations and body dissatisfaction in young women attempting to lose weight. J Hum Nutr Diet. (2014) 27:849. doi: $10.1111 /$ jhn. 12078

88. Urbańska A, Dziurawiec KZ. Obesity and body image. Curr Prob Psychiatry. (2019) 20:301-8. doi: 10.2478/cpp-2019-0022

89. Blodorn A, Major B, Hunger J, Miller C. Unpacking the psychological weight of weight stigma: a rejection-expectation pathway. J Exp Soc Psychol. (2016) 63:69-76. doi: 10.1016/j.jesp.2015.12.003

90. Posavac H, Posavac S, Posavac E. Exposure to media images of female attractiveness and concern with body weight among young women. Sex Roles. (1998) 38:187-201. doi: 10.1023/A:1018729015490
91. Gumble A, Carels R. The harmful and beneficial impacts of weight bias on well-being: the moderating influence of weight status. Body Image. (2012) 9:101-7. doi: 10.1016/j.bodyim.2011.07.005

92. Alexandrova-Karamanova A. Appearance self-attitudes and health and wellbeing of Bulgarian adolescents. Central Eur J Paediatr. (2020) 16:6982. doi: $10.5457 / \mathrm{p} 2005-114.258$

93. Finer N. Medical consequences of obesity. Medicine. (2015) 43:8893. doi: 10.1016/j.mpmed.2014.11.003

94. Kłósek P. Zalezności miedzy stresem psychologicznym a powstawaniem otyłości. Forum Medycyny Rodzinnej. (2016) 10:145-52.

95. Park A. Pathophysiology and aetiology and medical consequences of obesity. Medicine. (2019) 47:169-74. doi: 10.1016/j.mpmed.2018. 12.010

96. Kornhaber R, Visentin D, Thapa DK, West S, McKittrick A, Haik J, et al. Cosmetic camouflage improves quality of life among patients with skin disfigurement: a systematic review. Body Image. (2018) 27:98108. doi: 10.1016/j.bodyim.2018.08.004

97. Sommer R, Augustin M, Hilbring C, Ständer S, Hubo M, Hutt HJ, et al. Significance of chronic pruritus for intrapersonal burden and interpersonal experiences of stigmatization and sexuality in patients with psoriasis. J Eur Acad Dermatol Venereol. (2021) 35:1553-61. doi: 10.1111/jdv. 17188

98. Miniszewska J, Adamska M. Beliefs about health, illness and acceptance of the limitations of chronic somatic disease in people with psoriasis. Psychiatria i Psychologia Kliniczna. (2014) 14:202-12. doi: 10.15557/PiPK. 2014.0029

99. Polak D, Teległów A, Piotrowska A. Wpływ czynników psychologicznych na powstawanie i przebieg wybranych chorób skóry oraz znaczenie zaburzeń dermatologicznych w dobrostanie psychicznym. (2020) 9:455-60. doi: 10.6084/m9.figshare.13151012

Conflict of Interest: The authors declare that the research was conducted in the absence of any commercial or financial relationships that could be construed as a potential conflict of interest.

Publisher's Note: All claims expressed in this article are solely those of the authors and do not necessarily represent those of their affiliated organizations, or those of the publisher, the editors and the reviewers. Any product that may be evaluated in this article, or claim that may be made by its manufacturer, is not guaranteed or endorsed by the publisher.

Copyright $\odot 2021$ Mazurkiewicz, Krefta and Lipowska. This is an open-access article distributed under the terms of the Creative Commons Attribution License (CC BY). The use, distribution or reproduction in other forums is permitted, provided the original author(s) and the copyright owner(s) are credited and that the original publication in this journal is cited, in accordance with accepted academic practice. No use, distribution or reproduction is permitted which does not comply with these terms. 